\title{
COVID-19 in patients with gestational diabetes: review of literature
}

\section{ABSTRACT}

The risk of severe acute respiratory distress syndrome associated with coronavirus-2 (SARS-CoV-2) to maternal and newborn health has yet to be determined. Several studies showed that pregnancy with gestational diabetes increased the risk of maternal illness, but cases of gestational diabetes, preeclampsia and preterm birth have been reported rarely. Reports indicated placental infection and vertical transmission of COVID-19 were uncommon. Interestingly, despite the lack of SARS-CoV-2 placental infection, there were many records of major abnormalities in placental morphology. Continued research into offsprings of pregnant women with gestational diabetes infected with SARS-CoV-2 was vitally necessary. This study showed the impact of COVID infections on the fetus and the newborn in GDM pregnancy. There were very few data considering this subject and therefore, the findings have nowadays very debatable value. However, it's worthwhile to show the scientific community that nowadays we have no proof that COVID infection has a significant impact on pregnancy and the fetus. (Clin Diabetol 2020; 9; 6: 367-371)

Key words: COVID-19, patients, gestational diabetes

\section{Introduction}

Severe acute respiratory distress syndrome associated with coronavirus-2 (SARS-CoV-2), was an etiological agent of Coronavirus disease 2019 (COVID-19). It

Address for correspondence:

Mahdya Bukhari

King Saud University Medical City

Dariyah 53/1856/02 KKUH

00966 Riyadh, Saudi Arabia

e-mail: aelmalky@ksu.edu.sa

Clinical Diabetology 2020, 9; 6: 367-371

DOI: $10.5603 /$ DK.2020.0056

Received: 14.09 .2020

Accepted: 02.11.2020 was first identified in Wuhan, China, in December 2019 and is now a global pandemic. To date, more than 4 million cases and 300,000 deaths have been registered by the World Health Organisation. There has been a significant increase in awareness of the genetic, virological, epidemiological, and clinical aspects of COVID-19, but there are far fewer studies explaining the risks and unique impact of COVID-19 on pregnant females with gestational diabetes and their newly born infants. In this study, both peer-reviewed and non-peerreviewed preprints were included in order to identify the most up-to-date information.

Pregnancy with gestational diabetes increases the risk of adverse obstetric and neonatal outcomes due to many respiratory viral infections. The maternal immune system is altered during pregnancy in order to prevent the rejection of the fetus and to contribute to the development of the fetus [1]. Some viral infections cause more serious or prolonged illness in pregnant women with gestational diabetes [2]. COVID-19 has resulted in elevated rates of abortion, infant mortality and preterm delivery [3]. Multiple influenza studies have shown an increased risk of maternal morbidity and mortality relative to non-pregnant women. On the other hand, the majority of results for pregnant women with gestational diabetes infected with SARS-CoV-2 [5-53] do not vary from the general population. Fever is the most common symptom of COVID-19 in these patients, but many also experience cough, shortness of breath, and diarrhea. Occasionally serious infections involved mechanical ventilation [2-46] but rarely resulted in death $[4,5]$.

\section{COVID in pregnant women with gestational diabetes}

Although the majority of COVID infections in pregnant women with gestational diabetes were mild, data indicated substantial placental pathology 
in SARS-CoV-2 pregnancy despite lack of detectable or very low levels of SARS-CoV-2 mRNA or protein [4-43]. There were, however, case studies suggesting COVID-19 virons in syncytio-trophoblasts in placental villous when examined by the electron microscopy [6-8] or (PCR) $[5,28,36]$. The-significant questions that remains unanswered are, whether SARS-CoV-2 replicates in the placenta, whether it is the cause of the reported placenta abnormalities and, whether SARSCoV-2 is an "innocent bystander." It is also important to note that the identified placenta abnormalities occur mainly in women who are asymptomatic or have mild to moderate illness, indicating that these defects are not necessarily due to severe COVID disease.

\section{Placenta abnormalities}

\section{in diabetic women}

The placenta abnormalities identified in an infected diabetic pregnant women with SARS-CoV-2 include diffuse perivil fibrin, fetal vascular malperfusion in fetal vessels, choriohemangioma, maternal vascular malperfusion, and multifocal infarctions [17, 26, 36]. In some cases, SARS-CoV-2 has been found in the placenta $[5,17,28,36]$. Lack of controls and non-specific staining issues [16] complicate the interpretation of these findings in some of these studies. Importantly, the vast majority of placenta cases were negative for SARS-CoV-2 as calculated by PCR [12, 22, 26, 27, 36, $41,43]$. The anomalies observed in placenta pathology therefore indicated that the placenta was vulnerable to maternal COVID-19 disease, even in the absence of infection, because in many cases these disorders may be due to maternal co-morbidities such as hypertension, preeclampsia, and gestational diabetes. There is, therefore, a vital need for thorough systematic studies to determine the prevalence of infection and replication of SARS-CoV-2 in the placenta and its connection with placenta abnormalities.

\section{Easy vertical transmission?}

It still remains to be seen whether SARS-CoV-2 can be transferred from a diabetic pregnant woman to her fetus, a process called vertical transmission. Importantly, the transmission is predicted to have various effects over the three trimesters of pregnancy. Transplacental transmission of the virus typically increases with advanced gestational age, while there is a decreases in the incidence of fetal injuries from embryopathy and embryo/fetal death in the first trimester, from fetal infection and immune response during the second and third trimesters. Unlike many other viral diseases, viremia in SARS-CoV-2 is observed in just $1 \%$ of symptomatic patients and is usually mild and transient [19].

\section{Effect of COVID-19 on newly born infants}

Most of the case reports documented that, the birth of a full term baby to COVID-19 positive mothers with mild to moderate illness is not carrying any significant risk to the baby itself [8-53]. Preterm births, on the other hand, are fairly common in women with severe illness, although there are sporadic reports of spontaneous preterm births [9-53]. Spontaneous abortion has also been reported twice in early pregnancy $[5,45]$ and fetal death has been reported 6 times [13, $18,23,24]$. Case reports of newborns with symptoms requiring NICU admission for tachypnea, tachycardia, fever, gastrointestinal symptoms, and signs of CT pulmonary infection $[2,7,12,27,41,48,52,53]$ were reported; with 2 of 5 had NP swabs positive for SARS-CoV-2. Interestingly, some symptomatic infants tested negative for SARS-CoV-2. In one case, a positive SARS-CoV-2 infant born at 31 weeks of age needed resuscitation and was diagnosed with pneumonia, but the authors confirmed that they suspected sepsis with Enterobacter [52]. Thus, with the exception of these unusual cases, neonates were born healthy to infected mothers ofwith SARS-CoV-2. However, it has yet to be known whether infection at an earlier stage would have a significant effect on neonatal health and whether it results in long term outcomes.

\section{Actual mode of transmission}

Newborns may be infected by viral infection from mother either directly by the virus through vertical transmission or passively, by the maternal reaction to the virus. Considerable evidence indicates the absence of vertical transmission of SARS-CoV-2. Multiple newborns were screened for SARS-CoV-2 at delivery and viral RNA was not found in cord blood, throat and nasopharyngeal swabs, urine, and feces $[5,51]$. Amniotic fluid samples were also obtained from positive COVID pregnant mothers and were mainly screened negative for SARS-CoV-2 [5-49]. Neonatal testing, 24 hours or more after birth, have rarely been confirmed positive for the virus [27-52], but due to delays in testing, these infants may have already been infected after birth. There was one case report of COVID-19 neonates at birth, but the baby was symptom free with, perhaps, the exception of some minor initial nursing problems [28]. In addition, despite cautious isolation, the baby born at 33 weeks of age tested positive after 16 hours and again after 48 hours post-partum [2]. The authors indicated that this infant may have been infected either during the delivery of the ceasarean or in the uterus. The baby needed admission to the NICU for low Apgar scores and ventilator support. 


\section{Antibodies were found in neonatal blood}

Most babies in these studies were delivered by a cesarean section, and it is possible that newborns could potentially be contaminated during vaginal delivery. Vaginal swabs, however, were screened negative at 37 weeks of caesarean section delivery [12] and negative for SARS-CoV-2 in 6 women at hospital admission [45]. Intriguingly, despite the absence of virus present in neonate at birth, antibodies have been detected in neonatal tissue [51]. In particular, IgM has been documented to be elevated indicating fetal exposure to the uterine virus [51]. It is important to note that IgM antibody testing results in a high risk of false-positive [19] but these findings indicate that ongoing neonatal antibody testing can be useful.

\section{Extracellular vesicles confer viral resistance to receptor cells}

Overall, there is little evidence of vertical transmission in the majority of cases of positive COVID-19 birth. The fact that viremia is present in $1 \%$ of symptomatic patients and is usually mild and temporary may play a role [42]. However, other processes are likely to be just as important or more important in the defense of the fetus against vertical transmission. Maternal-fetal interface barriers protect the fetus from infection. For example, the syncytiotrophoblasts-organize the immune response to infection and also act as a physical barrier to the viral passage $[29,47]$. Immune cells in the placenta also have anti-viral potential [47]. Finally, previous studies have shown that trophoblast-derived extracellular vesicles containing a special group of miRNAs, expressed as chromosome 19 miRNA clusters, confer viral resistance to receptor cells suggesting a paracrine role that allows contact between placental cells to control their immunity to viral infections [10].

The ability of the virus to replicate and infect the placenta is also dependent on the virus. In the case of SARS-CoV-2, the entry of cells requires the binding of the spike protein to ACE2 [15]. The virus is then produced by cellular proteases such as TMPRSS2 [15] and possibly cathepsin B/L7 [37] and furin [6]. Utilizing recently reported single-cell RNAseq results, researchers have observed robust ACE2 activity in the placenta [21, 37] though not in TMPRSS2 [37]. Two studies, using single nucleotide RNAseq or single-cell RNAseq, were recently performed during gestation and found expression of ACE2 but either no or very low levels of TMPRSS2 were detected in the placenta [3, 32]. There has been no systematic assessment of the presence and role of other proteases that lead to viral entry and replication in the placenta cell. ACE2 was observed by $133 \mathrm{IHC}$ in syncytio-trophoblast, cyto-trophoblast, endo-thelial and smooth muscles of the blood vessels [40].

Interestingly, ACE2 is involved in placentation, including the migration of trophoblasts, vascular remodeling, and maternal vasodilation [33, 39]. Complications such as abortion, ectopic pregnancy, and preeclampsia have also been implicated in ACE2 [40]. Therefore, if SARS-CoV-2 affects the expression of ACE2 in the placenta as shown by SARS-CoV-1 in the lung [20], there is a risk for placental defects and complications of pregnancy. The existence of ACE2 in the placenta could mean that there is a capacity to bind COVID-19 to cause viral infection, but there are mechanisms that underlie SARS-CoV-2's failure to infect and replicate in the placenta are unknown.

\section{Conclussion}

Vertical transmission of SARS-CoV-2 is considered unlikely at this time but there appears to be considerable potential for SARS-CoV-2 to affect the placental function and fetal development. Continued research is, therefore, needed focusing especially on the detection of SARS-CoV-2 at early gestational time points. Finally, careful longitudinal studies with adequate controls are needed before any conclusions about COVID-19's maternal or neonatal effects are drawn.

\section{Conflict of interest}

The author declare no conflict of interest.

\section{REFERENCES}

1. Mor G, Aldo P, Alvero AB. The unique immunological and microbial aspects of pregnancy. Nat Rev Immunol. 2017; 17(8): 469-482, doi: 10.1038/nri.2017.64, indexed in Pubmed: 28627518.

2. Racicot K, Mor G. Risks associated with viral infections during pregnancyViral infections during pregnancy. J Clin Invest. 2017; 127: 1591-1599.

3. Wong SF, Chow KM, Leung TN, et al. Pregnancy and perinatal outcomes of women with severe acute respiratory syndrome. Am J Obstet Gynecol. 2004; 191: 292-297.

4. Hantoushzadeh S, Shamshirsaz AA, Aleyasin A, et al. Maternal death due to COVID-19. Am J Obstet Gynecol. 2020; 223(1): 109.e1-109.e16, doi: 10.1016/j.ajog.2020.04.030, indexed in Pubmed: 32360108.

5. Karami P, Naghavi M, Feyzi A, et al. WITHDRAWN: Mortality of a pregnant patient diagnosed with COVID-19: A case report with clinical, radiological, and histopathological findings. Travel Med Infect Dis. 2020 [Epub ahead of print]: 101665, doi: 10.1016/j. tmaid.2020.101665, indexed in Pubmed: 32283217.

6. Algarroba GN, Rekawek P, Vahanian SA, et al. Visualization of severe acute respiratory syndrome coronavirus 2 invading the human placenta using electron microscopy. Am J Obstet Gynecol. 2020; 223(2): 275-278, doi: 10.1016/j.ajog.2020.05.023, indexed in Pubmed: 32405074.

7. Hosier HFS, Morotti R, Deshmukh U, et al. First case of placental infection with SARS-CoV-2. J Clin Investig. 2020; 130(9): 4947-4953, doi: https://doi.org/10.1172/JCI139569. 
8. Patane L, Morotti D, Giunta MR, et al. Vertical transmission of coronavirus disease 2019: severe acute respiratory syndrome coronavirus 2 RNA on the fetal side of the placenta in pregnancies with coronavirus disease 2019-positive mothers and neonates at birth. Am J Obstet Gynecol MFM. 2020; 2(3): 100145. , doi: 10.1016/j.ajogmf.2020.100145.

9. Alzamora MC, Paredes T, Caceres D, et al. Severe COVID-19 during pregnancy and possible vertical transmission. Am J Perinatol. 2020; 37(8): 861-865, doi: 10.1055/s-0040-1710050, indexed in Pubmed: 32305046

10. Ashary N, Bhide A, Chakraborty $P$, et al. Single-Cell RNA-seq Identifies Cell Subsets in Human Placenta That Highly Expresses Factors Driving Pathogenesis of SARS-CoV-2. Frontiers in Cell and Developmental Biology. 2020; 8, doi: 10.3389/fcell.2020.00783.

11. Baergen RN, Heller DS. Placental Pathology in Covid-19 Positive Mothers: Preliminary Findings. Pediatr Dev Pathol. 2020; 23(3): 177-180, doi: 10.1177/1093526620925569, indexed in Pubmed: 32397896.

12. Baud D, Greub G, Favre G, et al. Second-trimester miscarriage in a pregnant woman with SARS-CoV-2 Infection. JAMA. 2020; 323(21): 2198-2200, doi: 10.1001/jama.2020.7233, indexed in Pubmed: 32352491

13. Bestle $D$, Heindl $M$, Limburg $H$, et al. TMPRSS2 and furin are both essential for proteolytic activation and spread of SARS-CoV-2 in human airway epithelial cells and provide promising drug targets. , doi: 10.1101/2020.04.15.042085.

14. Breslin N, Baptiste C, Gyamfi Bannerman C G. COVID 19 infection among asymptomatic and symptomatic pregnant women: Two weeks of confirmed presentations to an affiliated pair of New York City hospitals. Am J Obstet Gynecol MFM 100118. 2020.

15. Chen H, Guo J, Wang $C$, et al. Clinical characteristics and intrauterine vertical transmission potential of COVID-19 infection in nine pregnant women: a retrospective review of medical records. Lancet. 2020; 395(10226): 809-815, doi: 10.1016/S01406736(20)30360-3, indexed in Pubmed: 32151335.

16. Chen $L$, Li Q, Zheng $D$, et al. Clinical characteristics of pregnant women with Covid-19 in Wuhan, China. N Engl J Med. 2020; 382(25): e100, doi: 10.1056/NEJMc2009226, indexed in Pubmed: 32302077.

17. Delorme-Axford E, Donker RB, Mouillet JF, et al. Human placental trophoblasts confer viral resistance to recipient cells. Proc Natl Acad Sci U S A. 2013; 110(29): 12048-12053, doi: 10.1073/ pnas.1304718110, indexed in Pubmed: 23818581

18. Dong L, Tian J, He S, et al. Possible Vertical Transmission of SARSCoV-2 From an Infected Mother to Her Newborn. JAMA. 2020; 323(18): 1846-1848, doi: 10.1001/jama.2020.4621, indexed in Pubmed: 32215581

19. Fan C, Lei Di, Fang C, et al. Perinatal Transmission of COVID-19 Associated SARS-CoV-2: Should We Worry? Clin Infect Dis. 2020 [Epub ahead of print], doi: 10.1093/cid/ciaa226, indexed in Pubmed: 32182347

20. Hirshberg A, Kern-Goldberger AR, Levine LD, et al. Care of critically ill pregnant patients with coronavirus disease 2019: a case series. Am J Obstet Gynecol. 2020; 223(2): 286-290, doi: 10.1016/j. ajog.2020.04.029, indexed in Pubmed: 32371056.

21. Hoffmann $M$, Kleine-Weber $H$, Schroeder $S$, et al. SARS-CoV-2 cell entry depends on ACE2 and TMPRSS2 and is blocked by a clinically proven protease inhibitor. Cell. 2020; 181(2): 271-280.e8, doi: 10.1016/j.cell.2020.02.052, indexed in Pubmed: 32142651.

22. Honig A, Rieger L, Kapp M, et al. Immunohistochemistry in human placental tissue pitfalls of antigen detection. J Histochem Cytochem. 2005; 53(11): 1413-1420, doi: 10.1369/jhc.5A6664.2005, indexed in Pubmed: 16009964.

23. Kimberlin DW, Stagno S. Can SARS-CoV-2 infection be acquired in utero? More definitive evidence is needed. JAMA. 2020; 323(18): 1788-1789, doi: 10.1001/jama.2020.4868, indexed in Pubmed: 32215579

24. Kuba K, Imai $Y$, Rao S, et al. A crucial role of angiotensin converting enzyme 2 (ACE2) in SARS coronavirus-induced lung injury.
Nat Med. 2005; 11(8): 875-879, doi: 10.1038/nm1267, indexed in Pubmed: 16007097.

25. Li M, Chen L, Zhang J, et al. The SARS-CoV-2 receptor ACE2 expression of maternal-fetal interface and fetal organs by singlecell transcriptome study. PLoS One. 2020; 15(4): e0230295, doi: 10.1371/journal.pone.0230295, indexed in Pubmed: 32298273.

26. Li Y, Zhao R, Zheng S, et al. Lack of vertical transmission of severe acute respiratory syndrome coronavirus 2, China. Emerg Infect Dis. 2020; 26(6): 1335-1336, doi: 10.3201/eid2606.200287, indexed in Pubmed: 32134381.

27. Liu $Y$, Chen $H$, Tang $K$, et al. Clinical manifestations and outcome of SARS-CoV-2 infection during pregnancy. J Infect. 2020 [Epub ahead of print], doi: 10.1016/j.jinf.2020.02.028, indexed in Pubmed: 32145216.

28. Lokken E, Walker C, Delaney S, et al. Clinical characteristics of 46 pregnant women with a severe acute respiratory syndrome coronavirus 2 infection in Washington State. American Journal of Obstetrics and Gynecology. 2020, doi: 10.1016/j.ajog.2020.05.031.

29. Mulvey JJ, Magro CM, Ma LX, et al. Analysis of complement deposition and viral RNA in placentas of COVID-19 patients. Ann Diagn Pathol. 2020; 46: 151530, doi: 10.1016/j.anndiagpath.2020.151530, indexed in Pubmed: 32387855.

30. Nie R, Wang Ss, Yang Q, et al. Clinical features and the maternal and neonatal outcomes of pregnant women with coronavirus disease 2019. , doi: 10.1101/2020.03.22.20041061.

31. Pereira L. Congenital viral infection: traversing the uterineplacental interface. Annu Rev Virol. 2018; 5(1): 273-299, doi: 10.1146/annurev-virology-092917-043236, indexed in Pubmed: 30048217.

32. Pierce-Williams RAM, Burd J, Felder L, et al. Clinical course of severe and critical coronavirus disease 2019 in hospitalized pregnancies: a United States cohort study. Am J Obstet Gynecol MFM. 2020; 2(3): 100134, doi: 10.1016/j.ajogmf.2020.100134, indexed in Pubmed: 32391519.

33. Piersigilli F, Carkeek K, Hocq C, et al. COVID-19 in a 26-week preterm neonate. The Lancet Child \& Adolescent Health. 2020; 4(6): 476-478, doi: 10.1016/s2352-4642(20)30140-1.

34. Pique Regi R RR, Tarca A, Luca F, Xu Y, Alazizi A, Leng $Y, H s u ~ C$, Gomez Lopez N. Does the human placenta express the canonical cell entry mediators for SARS-CoV-2? https://elifesciences.org/ articles/58716.

35. Pringle KG, Tadros MA, Callister RJ, et al. The expression and localization of the human placental prorenin/renin-angiotensin system throughout pregnancy: roles in trophoblast invasion and angiogenesis? Placenta. 2011; 32(12): 956-962, doi: 10.1016/j. placenta.2011.09.020, indexed in Pubmed: 22018415.

36. Schwartz DA. An Analysis of 38 Pregnant Women with COVID-19, Their Newborn Infants, and Maternal-Fetal Transmission of SARSCoV-2: Maternal Coronavirus Infections and Pregnancy Outcomes. Arch Pathol Lab Med. 2020 [Epub ahead of print], doi: 10.5858/ arpa.2020-0901-SA, indexed in Pubmed: 32180426.

37. Shanes ED, Mithal LB, Otero $S$, et al. Placental Pathology in COVID-19. Am J Clin Pathol. 2020; 154(1): 23-32, doi: 10.1093/ ajcp/aqaa089, indexed in Pubmed: 32441303.

38. Sungnak W, Huang Ni, Bécavin C, et al. HCA Lung Biological Network. SARS-CoV-2 entry factors are highly expressed in nasal epithelial cells together with innate immune genes. Nat Med. 2020; 26(5): 681-687, doi: 10.1038/s41591-020-0868-6, indexed in Pubmed: 32327758.

39. Sutton D, Fuchs $K, D^{\prime}$ Alton $M$, et al. Universal Screening for SARSCoV-2 in Women Admitted for Delivery. N Engl J Med. 2020; 382(22): 2163-2164, doi: 10.1056/NEJMc2009316, indexed in Pubmed: 32283004.

40. Valdés G, Corthorn J, Bharadwaj MS, et al. Utero-placental expression of angiotensin-(1-7) and ACE2 in the pregnant guinea-pig. Reprod Biol Endocrinol. 2013; 11: 5, doi: 10.1186/1477-782711-5, indexed in Pubmed: 23339712.

41. Valdés $G$, Neves $L A A$, Anton $L$, et al. Distribution of angioten$\sin -(1-7)$ and ACE2 in human placentas of normal and pathologi- 
cal pregnancies. Placenta. 2006; 27(2-3): 200-207, doi: 10.1016/j placenta.2005.02.015, indexed in Pubmed: 16338465.

42. Wang S, Guo L, Chen L, et al. A case report of neonatal 285 COVID 19 infection in China. Clin Infect Dis. 2020; ciaa225, doi: 10.1093/cid/ciaa225.

43. Wang W, Xu Y, Gao R, et al. Detection of SARS-CoV-2 in Different Types of Clinical Specimens. JAMA. 2020; 323(18): 1843-1844, doi: 10.1001/jama.2020.3786, indexed in Pubmed: 32159775.

44. Wang X, Zhou Z, Zhang J, et al. A Case of 2019 Novel Coronavirus in a Pregnant Woman With Preterm Delivery. Clin Infect Dis. 2020; 71(15): 844-846, doi: 10.1093/cid/ciaa200, indexed in Pubmed: 32119083.

45. Yan J, Guo J, Fan C, et al. Coronavirus disease 2019 in pregnant women: a report based on 116 cases. Am J Obstet Gynecol. 2020; 223(1): 111.e1-111.e14, doi: 10.1016/j.ajog.2020.04.014, indexed in Pubmed: 32335053.

46. Yin M, Zhang L, Deng G, et al. Severe Acute Respiratory Syndrome Coronavirus 2 (SARS-CoV-2) Infection During Pregnancy In China: A Retrospective Cohort Study. BioRxiv. 2020, doi: 10.1101/2020.04.07.20053744.

47. Yockey $\sqcup$, Lucas $C$, Iwasaki A. Contributions of maternal and fetal antiviral immunity in congenital disease. Science. 2020; 368(6491): 608-612, doi: 10.1126/science.aaz1960, indexed in Pubmed: 32381717
48. Yu N, Li W, Kang Q, et al. Clinical features and obstetric and neonatal outcomes of pregnant patients with COVID-19 in Wuhan, China: a retrospective, single-centre, descriptive study. Lancet Infect Dis. 2020; 20(5): 559-564, doi: 10.1016/S14733099(20)30176-6, indexed in Pubmed: 32220284.

49. Yu N, Li W, Kang Q, et al. No SARS-CoV-2 detected in amniotic fluid in mid-pregnancy. Lancet Infect Dis. 2020 [Epub ahead of print], doi: 10.1016/S1473-3099(20)30320-0, indexed in Pubmed: 32333848.

50. Zambrano LI, Fuentes-Barahona IC, Bejarano-Torres DA, et al. A pregnant woman with COVID-19 in Central America. Travel Med Infect Dis. 2020; 36: 101639, doi: 10.1016/j.tmaid.2020.101639, indexed in Pubmed: 32222420.

51. Zeng $\mathrm{H}, \mathrm{Xu} \mathrm{C}$, Fan J, et al. Antibodies in Infants Born to Mothers With COVID-19 Pneumonia. JAMA. 2020; 323(18): 1848-1849, doi: 10.1001/jama.2020.4861, indexed in Pubmed: 32215589.

52. Zeng L, Xia S, Yuan W, et al. Neonatal Early-Onset Infection With SARS-CoV-2 in 33 Neonates Born to Mothers With COVID-19 in Wuhan, China. JAMA Pediatr. 2020; 174(7): 722-725, doi: 10.1001/jamapediatrics.2020.0878, indexed in Pubmed: 32215598.

53. Zhu H, Wang L, Fang $C$, et al. Clinical analysis of 10 neonates born to mothers with 2019-nCoV pneumonia. Transl Pediatr. 2020; 9(1): 51-60, doi: 10.21037/tp.2020.02.06, indexed in Pubmed: 32154135. 